\title{
T1, T2 Mapping and Extracellular Volume Fraction (ECV): Application, Value and Further Perspectives in Myocardial Inflammation and Cardiomyopathies
}

\author{
Anwendung, Nutzen und zukünftige Perspektive des T1- und \\ T2-Mapping sowie der extrazellulären Volumenfraktion (ECV) \\ bei myokardialer Inflammation und Kardiomyopathien
}

Authors

Affiliation
F. C. Roller, S. Harth, C. Schneider, G. A. Krombach

Diagnostic and Interventional Radiology, Justus-Liebig-University, Giessen, Germany

\author{
Key words \\ - cardiac \\ - MR imaging \\ - amyloidosis \\ - inflammation \\ - technical aspects
}

received $\quad 8.1 .2015$

accepted 26.3.2015

\section{Bibliography}

DOI http://dx.doi.org/ 10.1055/s-0034-1399546

Published online: 22.6.2015

Fortschr Röntgenstr 2015; 187: 760-770 @ Georg Thieme

Verlag KG Stuttgart - New York . ISSN 1438-9029

\section{Correspondence}

Herr Dr. Fritz Christian Roller

Radiologie, Universitätsklinikum Giessen

Klinikstraße 36

35392 Giessen

Germany

Tel.: ++ 49/06 41/98556329

Fax: ++49/06 41/98541809

fritz.c.roller@radiol.med.uni-

giessen.de

\section{Zusammenfassung}

$\nabla$

Die kardiale Magnetresonanztomografie (MRT) ist eine sehr vielseitig einsetzbare diagnostische Modalität. Einer ihrer Hauptvorteile liegt in der Möglichkeit Gewebecharakterisierung zu betreiben. Bisher wurden standardmäßig vor allem T1-gewichtete Sequenzen zur Bildgebung von fokalen myokardialen Narben bzw. Schädigungen und T2gewichtete Bilder für die Ödembildgebung genutzt. Andererseits sind diese Techniken insbesondere bei der Visualisierung von globalen myokardialen Veränderungen technisch bedingt stark limitiert. Aktuell entwickelte Techniken wie das T1- und das T2-Mapping oder auch die Bestimmung des „Extrazellulären Volumens“ ermöglichen uns hingegen eine Quantifizierung von globalen myokardialen Veränderungen und Pathologien wie bereits für Fibrose und Ödem aber auch für Amyloidose, Fett- bzw. Eisenspeichererkrankungen gezeigt werden konnte. Aufgrund der vielversprechenden Ergebnisse, ihrer Robustheit sowie einer Quantifizierung von T1- und T2-Zeiten erlauben uns diese Techniken in Zukunft eine Detektion von frühen Krankheitsstadien oder eignen sich darüber hinaus vielleicht auch für eine Therapiemonitoring und eine Prognoseabschätzung im Rahmen von Verlaufskontrollen.

Kernaussagen:

- Die kardiale MRT ermöglicht eine Gewebecharakterisierung mittels T1- und T2-gewichteten Sequenzen.

- Bei globalen bzw. diffusen myokardialen Veränderungen sind diese Sequenzen jedoch limitiert und schränken die korrekte Bildinterpretation ein.

- Im Gegensatz dazu ermöglichen T1-, T2-Mapping und ECV eine Quantifizierung globaler myokardialer Veränderungen.

- Bei sehr vielen unterschiedlichen Erkrankungen konnten Veränderungen von T1 und T2 Relaxationszeiten gezeigt werden (z.B. Myokarditis)

\section{Abstract \\ $\nabla$}

Cardiac magnetic resonance imaging (CMRI) is a versatile diagnostic tool. One of its main advantages is the possibility of tissue characterization. T1-weighted images for scar and T2-weighted images for edema visualization are key methods for tissue characterization. Otherwise these sequences are strongly limited for the detection of diffuse myocardial pathologies. Recently, rapid technical innovations have generated new techniques. T1, T2 mapping and evaluation of the extracellular volume fraction (ECV) allow quantification of diffuse myocardial pathologies and showed great potential in the visualization of fibrosis, edema, amyloid, iron overload and lipid. In the future these techniques might enable the detection of early cardiac involvement, even act as a prognosticator. Moreover, therapy monitoring and follow-up might be possible due to versatile parameter quantification with these new techniques.

Key points:

- CMR allows for tissue characterization via T1and T2-weighted sequences.

- In cases of diffuse, global myocardial pathologies, correct image interpretation with traditional CMR sequences might be difficult.

- T1, T2 mapping and ECV can quantify diffuse, global myocardial pathologies.

- Alterations of myocardial T1 and T2 relaxation times occur in various myocardial diseases (e. g. acute myocarditis).

- In the future mapping might act as a prognosticator or therapy monitoring tool.

Citation Format:

- Roller FC, Harth S, Schneider C et al. T1, T2 Mapping and Extracellular Volume Fraction (ECV): Application, Value and Further Perspectives in Myocardial Inflammation and Cardiomyopathies. Fortschr Röntgenstr 2015; 187: 760-770 
- Zukünftig könnte Mapping auch in der Prognose und im Therapiemonitoring eine bedeutende Rolle zukommen

\section{Introduction}

$\nabla$

Cardiovascular magnetic resonance (CMR) is an essential and powerful diagnostic tool for the evaluation of cardiac diseases. It represents the gold standard in the quantification of cardiac function and is clinically established for the characterization of myocardial tissue and perfusion. According to the consensus recommendations of the "German Societies of Radiology and Cardiology", CMR is the preferred alternative for many clinical issues [1].

One of CMRs key unique advantages is the possibility of tissue characterization. Current sequences weighted to a magnetic property, like T1 relaxation for scar imaging, which is also known as late gadolinium enhancement (LGE), and T2 relaxation for edema visualization, are preferentially used and only allow qualitative image analysis. However, the corresponding sequences are subject to several limitations, and especially, T2-weighted sequences are known to be prone to artifacts from many different sources. For example, the use of phased array coils can cause signal intensity inhomogeneity, which may obscure myocardial edema. Consequently, interpretation is often challenging and subjective. A major drawback is the inability to delineate global myocardial pathologies such as pan-inflammation or diffuse fibrosis.

In the last couple of years, newer techniques, namely T1 and T2 mapping, have been developed and advanced rapidly. Up to now mapping is increasingly available and integrated in clinical routine settings. Both T1 and T2 mapping are robust single breathhold sequences (mainly performed in diastole short-axis views) and are characterized by creating colored pixel maps (maps on console are not colored) where each pixel value represents the corresponding T1 or T2 (or T2*) values. Particularly some different T1 mapping techniques are applied and influencing factors on T1 mapping and ECV values are described and discussed in the recent literature [2,3]. In contrast to T2 mapping, T1 mapping can be performed without contrast agent administration (as native T1 mapping) but also after contrast agent administration (as post-contrast T1 mapping).

Compared to healthy volunteers, native $\mathrm{T} 1$ values are higher in diseases causing an increase in the extracellular compartment. This has already been demonstrated for fibrosis [4], edema [5] and amyloid [6]. Lower native T1 relaxivity compared to healthy volunteers was shown in Fabry disease [7] and iron overload [8]. Shortened T1 times in post-contrast T1 mapping are consistent with the presence of diffuse myocardial fibrosis, which could be shown for heart failure [9], ischemic heart disease [10] and in patients with diabetes [11].

The post contrast T1 mapping values are influenced by the speed of renal clearance, gadolinium dose, acquisition time post bolus injection, hematocrit level, and body composition. Therefore, measuring the extracellular volume fraction (ECV) by subtracting preand post-contrast maps with hematocrit correction at a sufficient equilibrium, which is normally reached after 15 minutes post bolus injection, was identified as a better alternative [12-14]. ECV is a specific parameter for extracellular expansion and is also well validated. ECV is calculated according to the formula: ECV $=(1-$ hematocrit $)^{*}$ (1 / T1 myocardium post-contrast - 1 / T1 myocardium pre-contrast) / (1 / T1 blood post-contrast - 1 / T1 blood pre-contrast). Amyloid and areas of involved myocardium in myocardial inflammation, for example, showed far higher ECV values than other cardiac diseases [12]. Even a connection between elevated ECV and mortality prediction was reported. In a study with 793 patients suffering from ischemic heart disease, ECV showed potential in the prediction of short-term mortality [15].

T2 mapping, however, enables the identification of myocardial edema in acute infarction and inflammatory disease [16]. Despite improved quantitative assessment of edema also global edema or pan-myocardial inflammation seems to be detectable. In cases of transplant reactions, for example, it could also be demonstrated that even early reactions, which were missed by other imaging modalities, could be detected [17].

In summary, global myocardial tissue changes or involvement can be detected already in early stages of different diseases, and also without contrast media administration by native T1 mapping. The results for both techniques are very promising and mapping is the subject of many current studies in the field of cardiac imaging. The aim of this review article is to highlight the additional value of T1 mapping, T2 mapping and ECV in cardiomyopathies and myocardial inflammation.

\section{Methods and technical comments: \\ $\nabla$}

\section{Scanning protocol}

All imaging was performed with a 1.5 Tesla scanner (Avanto, Siemens Healthcare, Erlangen, Germany) using a dedicated cardiac coil and CMR protocol containing axial, coronal and sagittal thoracic survey images, steady state free precision (SSFP) sequences aligned to 2 chamber view (CV), $3 \mathrm{CV}, 4 \mathrm{CV}$ and short axis (SA), black-blood and LGE imaging, T1 and T2 mapping.

\section{Mapping}

Different T1 mapping techniques can be implemented and all techniques deal with different limitations regarding accuracy, precision and reproducibility [3]. On the one hand inversion recovery (IR) sequences, such as the modified look locker inversion recovery (MOLLI) method, are widely available and fully developed. Magnetization transfer hampers the accuracy of MOLLI significantly, whereas the precision is excellent and also a great value of reproducibility is achieved. Measured T1 times therefore are underestimated but precise and are reproducible using IR sequences. On the other hand saturation recovery (SR) methods, such as saturation recovery single-shot acquisition (SASHA), offer a greater value of accuracy because they are less sensitive to magnetization transfer and other limiting factors, but these sequences are noisier and more prone to artifacts. The measured T1 times are more accurate but also more imprecise with a smaller level of reproducibility compared to IR sequences. Actually, a combined IR/SR approach can also be performed and is known as saturation pulse prepared heart rate independent inversion recovery (SAPPHIRE). This approach has many of the benefits of IR and SR sequences but still deals with IR problems.

In our patients T1 mapping was performed as MOLLI sequence [18] and T2 mapping was performed with a standardized T2-prepared single shot SSFP sequence as previously reported [16].

T1 mapping: Data were obtained in end-diastole using a cardiacgated, SSFP-based MOLLI technique. Imaging parameters were: slice thickness: $8 \mathrm{~mm}$; spatial resolution: $2.2 \times 1.8 \times 8 \mathrm{~mm} ; 6 / 8$ 
partial Fourier acquisition; field of view: $240 \times 340 \mathrm{~mm}^{2}$; matrix: $192 \times 124$; flip angle $35^{\circ}$; TR 740 and TE 1,06; TI $100 \mathrm{~ms}$ and TI increment $80 \mathrm{~ms}$; trigger delay: $300 \mathrm{~ms}$; inversions: 3; acquisition heartbeats: 3,3,5; scan time: 17 heartbeats.

T2 mapping: Three SSFP images were acquired at end-diastole within one breath-hold. Imaging parameters were: slice thickness: $6 \mathrm{~mm}$; TR $3 \times \mathrm{RR}$; echo spacing $2.5 \mathrm{~ms}$; flip angle $70^{\circ}$; T2preparation times (T2p): $0 \mathrm{~ms} / 24 \mathrm{~ms} / 55 \mathrm{~ms}$; field of view: $244 \times 300 \mathrm{~mm}^{2}$ to $325 \times 400 \mathrm{~mm}^{2}$ depending on heart rate; matrix $104 \times 160$; bandwidth $947 \mathrm{~Hz} /$ pixel; acceleration factor 2 . To correct for residual cardiac and respiratory motion between image sets, a non-rigid registration algorithm was used.

\section{Post-contrast imaging}

Gadobenate dimeglumine (BOPTA) with a dose of $0.15 \mathrm{mmol} / \mathrm{kg}$ was injected, LGE imaging was performed 12 minutes after contrast media injection, and post-contrast T1 mapping was performed 15 minutes after contrast media injection (a bolus only approach was used for ECV measurements).

\section{Qualitative and quantitative image assessment}

All original images were assessed regarding artifacts due to susceptibility and cardiac, diaphragmatic or respiratory motion. Each motion-corrected series was evaluated for correct image alignment and each map was evaluated as to whether the original images were transformed to an acceptable map.

\section{Measurement of T1 and T2:}

After image acquisition T1 and T2 maps were generated after inline motion correction from the MR workstation. T1 times were measured for myocardium and blood pool in regions of interest (ROI) pre and post contrast administration. T2 times were measured in myocardial ROIs. It was emphasized that the ROIs were drawn only on the compact myocardium and did not include the myocardial borders because partial volume averaging artifact and registration error with gradual $\mathrm{T} 1$ value changes are present when measuring border areas between the myocardium and the LV cavity even after motion correction. Fig. 1 shows the native $\mathrm{T} 1$, post-contrast T1 map and T2 map in a 36-year-old healthy subject at basal short-axis level. In all presented case studies standardized global and focal T1, T2 mapping and ECV measurements were performed.

\section{Imaging in myocardial inflammation (myocarditis) and cardiomyopathies} $\nabla$

\section{Myocardial inflammation}

Myocarditis is a common disease and is the underlying cause in $12 \%$ of cases of sudden death in young adults [19]. Myocarditis is often defined as inflammation of myocardial tissue and is responsible for secondary myocardial diseases, such as dilated cardiomyopathy [20]. Clinical examination, electrocardiogram, echocardiography and serology often lead to an unsatisfactory diagnostic accuracy. For example Troponin $\mathrm{T}$ is only present in 35 - 45 \% biopsy-proven myocarditis caese[21]. Regional and global wall motion abnormalities are common in myocarditis [22]. Otherwise cardiac dysfunction is not specific for myocardial inflammation and its sensitivity is limited $[23,24]$.

To overcome these diagnostic difficulties, endomyocardial biopsy (EMB) with immunohistochemistry is a further diagnostic option, which is widely accepted in the diagnostic cascade of myocardial inflammation. The overall complication rate of EMB is described as $6 \%$ with severe complications appearing in $0.1 \%$ to $0.5 \%$ [25]. Considering the addressed risks in conjunction with its invasive character, EMB seems not to be justifiable in patients with less severe disease stages. For these patients CMR is used as a standard diagnostic tool and is characterized by a high degree of safety. The diagnosis of myocarditis with CMR is based on the Lake Louise criteria, which are described in the JACC White Paper by Friedrich et al. [26]. According to the Lake Louise criteria, myocardial inflammation is present if at least 2 of the 3 following criteria are met: regional or global signal intensity increase in T2-weighted images (ER/edema ratio), increased global myocardial early enhancement ratio between myocardium and skeletal muscles on post-contrast T1-weighted images (early gadolinium enhancement ratio/EGER) and at least one focal myocardial lesion on LGE images with a non-ischemic distribution. If typical LGE is
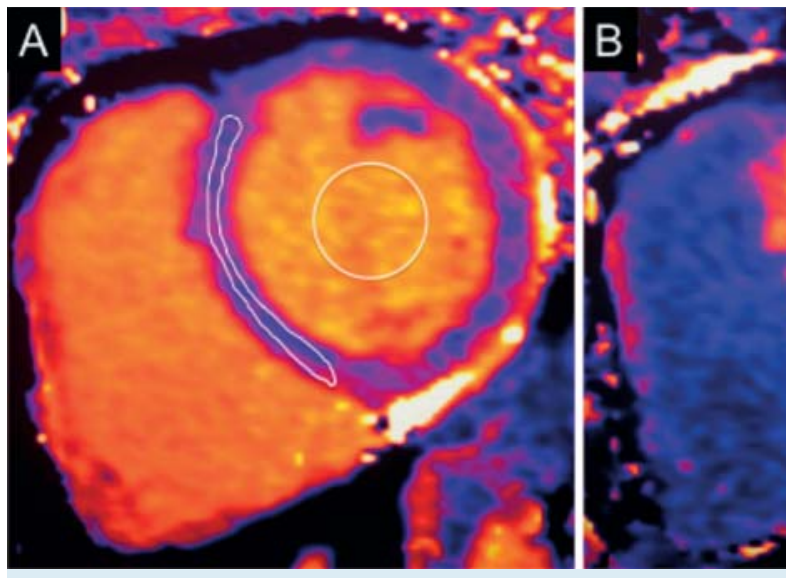

Fig. 1 Shows the native T1 map A, T1 map post contrast administration B and T2 map C of a 36-year-old male healthy subject at the basal short-axis level. The $\mathrm{T} 1$ and $\mathrm{T} 2$ values were measured within the spetal myocardium in ROIs ("regions of interest", white oval). The corresponding values are: Native T1 970 ms, post-contrast T1 405 ms and ECV of 0.24 (hematocrit level $0.4)$.
Abb. 1 Zeigt die native T1 map A, postkontrast T1 map B und T2 map bei einer gesunden männlichen 36-jährigen Versuchsperson. Die T1- und T2-Zeiten wurden im septalen Myokard in ROls („regions of interest“) gemessen (weißes oval) und ergaben folgende Werte: Native T1-Zeit 970 ms, postkontrast T1-Zeit 405 ms und T2-Zeit 53 ms. Aus der nativen T1-Zeit und der postkontrast T1-Zeit ergibt sich bei einem Hämatokrit von 0,4 ein korrespondierendes ECV von 0,24. 

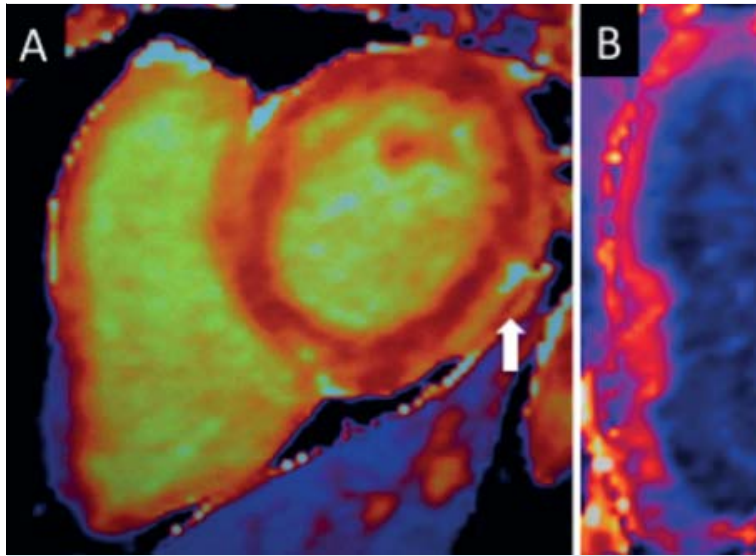

Fig. 2 Shows the native T1 map A, T1 map post contrast administration B and the corresponding LGE image $C$ of a 46-year-old male patient at the basal short-axis level. In all images a streaky subepicardial and rather intramyocardial appearance of the inferolateral is present (white arrow), which is compatible with myocardial inflammation. The native $\mathrm{T} 1$ time within this region is increased with up to $1057 \mathrm{~ms}$ and the $\mathrm{T} 1$ time post contrast media administration is decreased with about $350 \mathrm{~ms}$. The corresponding ECV in the involved myocardial area is elevated $(0.30)$ compared to areas of remote myocardium, for example in the septal myocardium ( $\mathrm{T} 1$ values pre an post contrast administration are $970 \mathrm{~ms}$ and $430 \mathrm{~ms}$, respectively, with a corresponding ECV of 0.24).
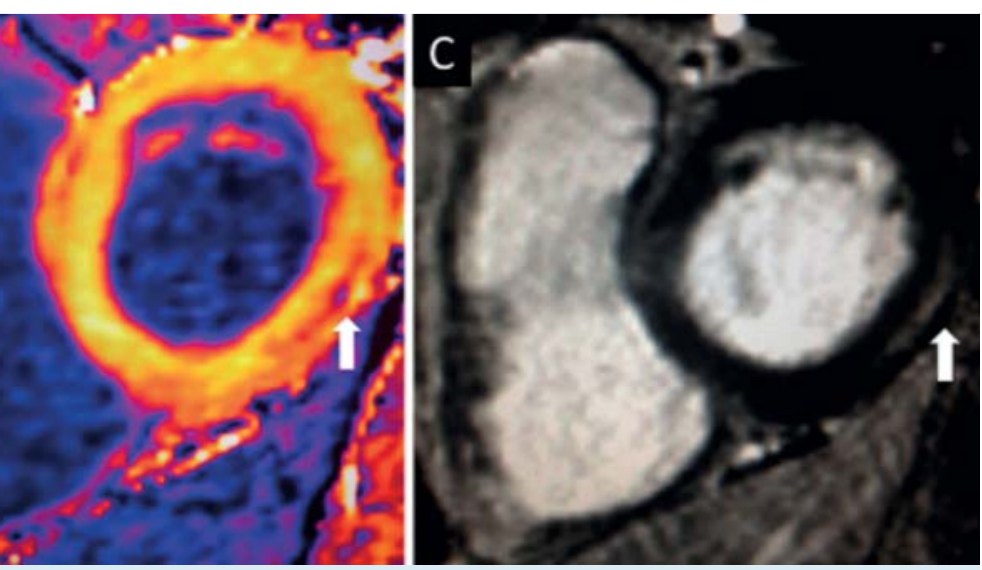

Abb. 2 Zeigt ein natives T1-Mapping-Bild A, ein postkontrast T1-MappingBild $\mathbf{B}$ und das korrespondierende LGE-Bild $\mathbf{C}$ bei einem 46-jährigem männlichen Patienten auf basal Kurzachsenschnitten. Alle Bilder zeigen streifige subepikardiale partiell intramyokardiale Veränderungen der Inferolateralwand (weißer Pfeil) vereinbar mit einer klassischen Verteilung bei myokardialer Inflammation. Die native T1-Zeit ist in diesem Areal auf $1057 \mathrm{~ms}$ erhöht, die postkontrast T1-Zeit ist hingegen auf $350 \mathrm{~ms}$ reduziert. Das korrespondierende ECV beträgt 0,30 und ist verglichen zu Arealen mit normalem Myokard erhöht ( $\mathrm{T} 1$ nativ $970 \mathrm{~ms}$, T1 postkontrast $430 \mathrm{~ms}$, ECV 0,24). visible in the initial CMR as the only criterion, myocardial injury caused by inflammation is present. Through application of the Lake Louise criteria, the diagnostic accuracy was improved from $68 \%$ to $78 \%$ compared to LGE alone [26]. In the light of newly developed mapping sequences, the question arises which further increment might be feasible or how either T1 or T2 mapping can lead to additional benefits. Luetkens et al. showed that native T1 times were significantly longer compared to healthy subjects in myocarditis. [27]. Moreover, it could be demonstrated by Ferreira et al. in 50 patients with suspected acute myocarditis that native T1 mapping is superior to T2-weighted black blood imaging and LGE imaging in the detection of myocarditis regarding sensitivity when assuming a native T1 cut-off value of $990 \mathrm{~ms}$ [28]. Furthermore, in a study by Hinojar et al., native T1 mapping enabled not only differentiation between healthy subjects and myocardial inflammation, but also of acute myocardial inflammation and convalescent disease stages [29].

In a phantom study by Giri et al., T2 mapping offered the potential for increased accuracy in the detection of myocardial edema [30] and in a study by Thavendiranathan et al. T2 mapping delineated a greater extent of myocardial disease in myocarditis and takotsubo cardiomyopathy compared to other sequences [16]. A T2 cut-off value of $59 \mathrm{~ms}$ identified areas of involved myocardium with a sensitivity and specificity of $94 \%$ and $97 \%$. Last but not least, ECV is also far higher in involved myocardium in different diseases [12]. Radunski et al. demonstrated that ECV in combination with LGE imaging significantly improved the diagnostic accuracy in patients with severe myocarditis compared to the standard Lake Louise criteria [31].

In a comparison of the results of Ferreira et al., Hinojar et al. and Radunski et al., the following should be noted [28, 29, 31]: 1.) Ferreira et al. investigated 60 patients with suspected acute myocarditis and showed an area under the curve (AUC) of 0.94 in the receiver operating curve (ROC) analysis for native T1 mapping or LGE (patients underwent CMR within a median of 2 days after onset of symptoms). 2.) Hinojar et al. investigated 61 patients with acute symptoms of myocarditis and 67 patients in convalescent myocarditis stages. They presented an AUC of 1.0 in the ROC analysis for native T1 mapping versus an AUC of 0.89 in the ROC analysis for the combination of native T1 and LGE in acute myocarditis, and an AUC of 0.98 in the ROC analysis for native T1 mapping in combination with LGE versus an AUC of 0.84 for native T1 mapping in convalescent disease stages (patients with acute myocarditis underwent CMR within a median of 3 days, and patients in convalescent disease stages underwent CMR within a median of 2 months after the onset of symptoms). 3.) Radunski et al., however, investigated 104 patients with myocarditis and showed an AUC of 0.86 in the ROC analysis for an ECV level $\geqq 0.29$, which was superior to native T1 mapping in their study population (patients with myocarditis underwent CMR within a median of 2 weeks after onset of symptoms). In summary, it can be stated that both native T1 mapping and ECV are superior to the Lake Louise criteria for the diagnosis of myocarditis, and that native T1 mapping might be influenced by the time between the onset of symptoms and CMR. Therefore, native T1 mapping might be preferentially used in patients with acute myocarditis, whereas the combination of native T1 mapping and LGE might be preferentially used in convalescent disease stages to achieve a high level of diagnostic accuracy.

- Fig. 2 shows typical subepicardial streaky myocardial LGE at the basal short-axis level in a 46-year-old male patient and the corresponding T1 maps pre and post contrast media injection in myocardial inflammation. Fig. 3 also demonstrates typical streaky subepicardial and myocardial LGE in a 21-year-old male patient with acute myocardial inflammation at the basal and midventricular short-axis level and the corresponding T2 maps. 

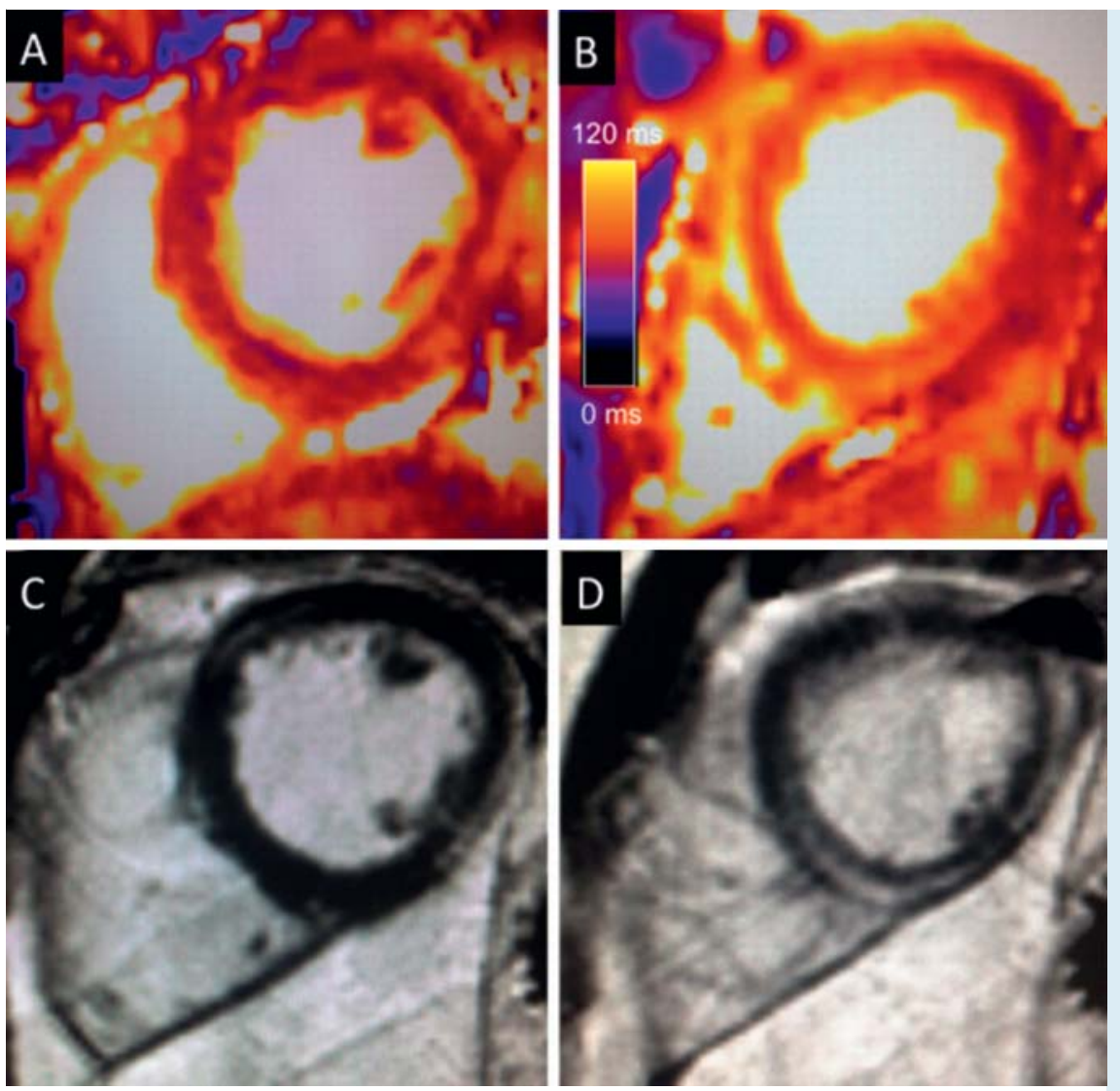

Fig. 3 Shows T2 mapping images and corresponding LGE images of a 21-year-old male patient with acute myocardial inflammation at the midventricular A, C and apical B, D short-axis level. In all images streaky subepicardial and intramyocardial involvement is displayed. Within images A, C, the streaky subepicardial involvement is inferolateral also with anterior involvement. In B, D significant intramyocardial involvement with an extension from anterolateral to anteroseptal is displayed. The T2 times in areas of focal involvement are clearly increased between $60 \mathrm{~ms}$ and $80 \mathrm{~ms}$, which is consistent with myocardial edema in myocardial inflammation. In areas of unaffected myocardium, the $\mathrm{T} 2$ values are below $60 \mathrm{~ms}$.

Abb.3 Zeigt T2-Mapping-Bilder und die korrespondierenden LGE-Bilder bei einem 21-jährigen männlichen Patienten mit akuter myokardialer Inflammation auf mittventrikulären $\mathbf{A}, \mathbf{C}$ und apikalen B, D Kurzachsenschnitten. In allen Bildern zeigt sich eine streifige subepikardiale und intramyokardiale Beteiligung im Rahmen der myokardialen Inflammation. In A, C sind die myokardialen Veränderungen inferolateral und anterior lokalisiert, in $\mathbf{B}, \mathbf{D}$ ist die kardiale Beteiligung sehr ausgeprägt und erstreckt sich von der Inferolateralwand aus über die Hinterwand bis nach anterior in das Septum. Die T2-Zeit beträgt in den betroffenen Arealen deutlich über $60 \mathrm{~ms}$ mit Spitzenwerten über $80 \mathrm{~ms}$, während im nicht betroffenen Myokard T2 Werte von deutlich unter $60 \mathrm{~ms}$ gemessen werden.

\section{Cardiomyopathies}

Hypertrophic cardiomyopathy (HCM)

HCM is caused by gene mutations in sarcomere proteins [32,33] and has a prevalence of $0.2 \%$ in the general population [34]. HCM is the most common monogenic cardiac disorder and is a common cause of sudden death in the young population [35]. Varying degrees of myocardial fibrosis are present in HCM [36] and the occurrence of myocardial fibrosis correlates with wall thickness, wall motion abnormalities [37] and ventricular tachycardia [38]. Focal fibrotic infiltrations can be detected via LGE imaging and LGE might also be useful as a biomarker for risk stratification and therapeutic monitoring [39-42]. Otherwise, LGE imaging is limited, or is unable to detect diffuse fibrotic infiltrations $[43,44]$ and it relies on a comparison between unaffected normal myocardium and regions of focal myocardial damage. Furthermore, qualitative assessment of LGE is operator-dependent and reliable comparison between scans or individuals can be difficult.

The additional benefits of T1 mapping in HCM might overcome these problems due to quantification of $\mathrm{T} 1$ on a voxel-wise basis. Also detection of early disease stages and diffuse fibrotic infiltrations in HCM might be possible. In the latest published data different T1 mapping techniques showed a good correlation to histologically quantified fibrosis [45-47]. In a study by Dass et al., for example, native T1 values in patients with HCM were significantly higher even in LGE unaffected myocardial tissue areas compared to healthy volunteers [4]. In addition, myocardial post-contrast $\mathrm{T} 1$ times are significantly lower in HCM compared to healthy volunteers [48] and are inversely correlated to the degree of fibrosis [46]. Finally, ECV values are significantly elevated in HCM and also in HCM sarcomere mutation carriers, even in the absence of left ventricular hypertrophy [49]. In the future early detection of global myocardial changes due to quantification of ECV might also assist disease-modifying therapies targeting interstitial myocardial fibrosis [49]. O Fig. 4 shows the native T1 map and post-contrast T1 map at the basal short-axis level in a 27-year-old male patient with HCM.

\section{Dilated cardiomyopathy (DCM)}

After coronary artery disease DCM is the second most common cause of heart failure [50 - 52]. Some DCM patients remain stable or even recover with normal ventricular function, while others are symptomatic and may develop arrhythmia or progressive heart failure [49]. DCM is characterized by a complex pathophysiology. Impaired myocardial energetics, myocardial edema, myocardial fibrosis and structural remodeling processes are present in DCM [49]. As in HCM, CMR plays a major role in the diagnosis of DCM due to the previously addressed possibility of tissue characterization. LGE imaging can assess focal myocardial fibrosis and its presence has also recently been identified as a predictor of cardiac death in DCM [52]. On the other hand the quantification of fibrosis achieved by LGE has several limitations as mentioned in the HCM section, and mapping seems to be also approach in DCM. In a 3-Tesla CMR study by Dass et al. native T1 values in DCM were elevated compared to healthy volunteers and the authors concluded that native T1 mapping detects underlying disease processes beyond those assessed by LGE imaging in relatively low-risk individuals [4]. A study by Puntman et al. showed similar results [53]. Also abnormally elevated ECV values were shown in patients with presence of non-ischemic DCM [54]. In a recent study by Nishii et al. T2 mapping showed that the myocardial water content was greater in patients with DCM compared to 

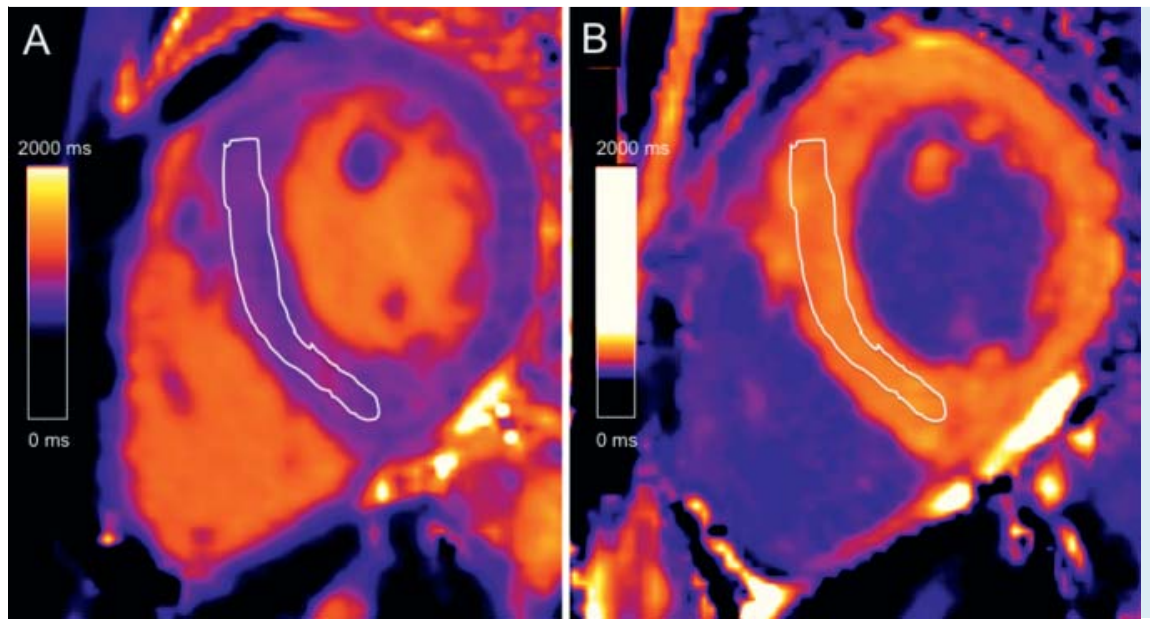

Fig. 4 Shows the pre- and post-contrast T1 map in a 27-year-old male patient with HCM at the midventricular short-axis level. The septal myocardium is clearly thickened with a diameter of $17 \mathrm{~mm}$. The native $\mathrm{T} 1$ value is $1050 \mathrm{~ms}$ and the post-contrast value is $370 \mathrm{~ms}$ within the ROI (white oval) in the septal myocardium. The corresponding ECV is 0.31 .

Abb. 4 Zeigt die native T1 map und die postkontrast $\mathrm{T} 1$ map bei einem 27-jahrigen Patienten mit HCM auf mittventrikulären Kurzachsenschnitten. Die native T1-Zeit beträgt $1050 \mathrm{~ms}$ und die postkontrast T1-Zeit 370 ms innerhalb des ROI im septalen Myokard (weißes oval). Das korrespondierende ECV hat einen Wert von 0,31.
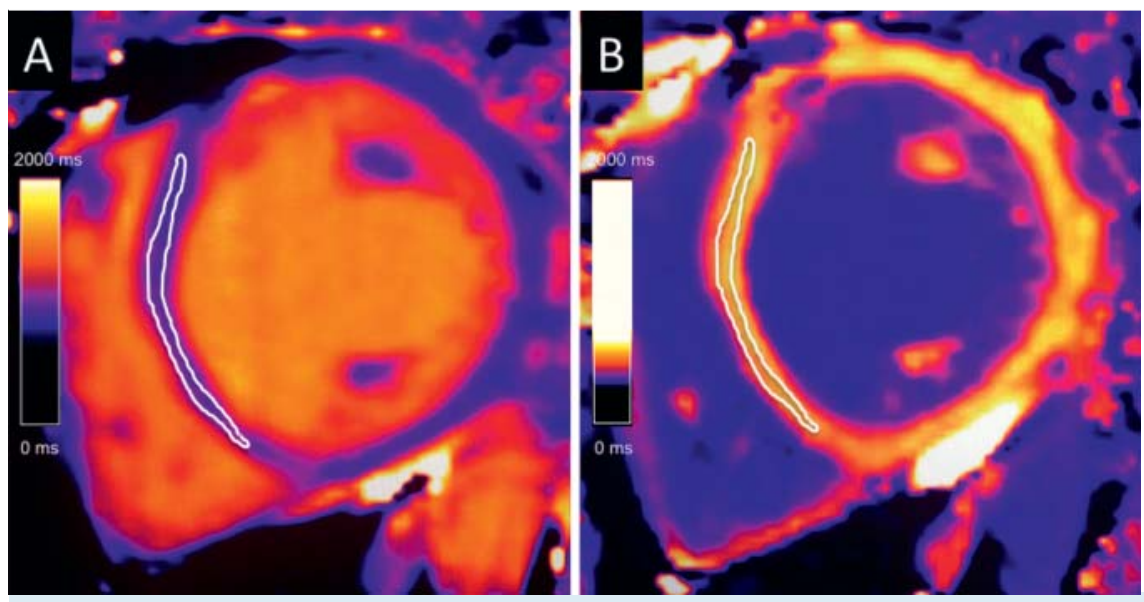

Fig. 5 Shows the pre- and post-contrast T1 map in a 64-year-old female patient at the basal short-axis level. The left ventricle is clearly enlarged and thinned out. The enddiastolic diameter is $63 \mathrm{~mm}$ and the septal wall thickness is only $5 \mathrm{~mm}$. The $\mathrm{T} 1$ times were measured in the septal myocardium (white curved lines). Within these areas the native $\mathrm{T} 1$ time was $1109 \mathrm{~ms}$ and the post-contrast T1 time was $330 \mathrm{~ms}$. The corresponding ECV is 0.32 . All values are consistent with myocardial fibrosis in DCM.
Abb.5 Zeigt ein natives T1-Bild und ein T1-Bild nach KM-Applikation bei einer 64-jährigen weiblichen Patientin auf basalen Kurzachsenschnitten. Der linke Ventrikel ist deutlich dilatiert und das Myokard ist ausgedünnt. Der enddiastolische Diameter beträgt $63 \mathrm{~mm}$, die septale Wand misst nur $5 \mathrm{~mm}$. Die T1-Zeit im septalen Myokard (weißer Messbereich) beträgt nativ 1109 ms und nach KM-Applikation 330 ms. Hieraus resultiert ein ECV von 0,32 . Die gemessenen Werte quantifizieren die Fibrose im Rahmen der DCM. normal controls and increased in progressive disease stages [55]. Based on their results, the authors concluded that T2 mapping is a useful technique for the diagnosis and quantification of diffuse myocardial edema in DCM [55]. \& Fig. 5 shows the T1 maps pre and post contrast media administration in a 64-year-old female patient with DCM.

\section{Amyloidosis}

In amyloidosis insoluble fibrils accumulate in the extracellular space caused by protein misfolding. As a consequence, the structure and function of many tissues and solid organs including the heart can be damaged [56]. Cardiac involvement is common in primary amyloid light chain (AL) amyloidosis and contributes substantially to morbidity and mortality $[57,58]$. Endomyocardial biopsy (EMB) is the gold standard for diagnosis in amyloidosis but is not routinely performed, because of its invasive character and the known associated risks. As further shown, CMR with LGE has great potential for tissue characterization in patients with amyloidosis [59-62]. CMR provides noninvasive diagnosis of patients with cardiac amyloidosis due to the identification of characteristic global or subendocardial LGE patterns. This characteristic LGE pattern is a hallmark for cardiac involvement, and when present, it also correlates with the prognosis of amyloidosis $[59,61]$. On the other hand, LGE imaging in patients with suspected cardiac amyloidosis also deals with several problems: gadolinium administration in patients with renal impairment is problematic or even impossible, and the presence of atypical disease patterns with patchy LGE infiltrations and appearances in different locations, which can be present in patients with lifethreatening disease, renders diagnosis more difficult $[56,59,62]$. In this context native $\mathrm{T} 1$ mapping offers great potential for accurate identification of amyloidosis [6]. Compared to other diseases, the native $\mathrm{T} 1$ values are much higher in amyloidosis and the ECV values are also clearly elevated as further studies showed $[6,63]$. Therefore, T1 mapping might be applicable as an early disease marker due to the detection of global myocardial changes. 

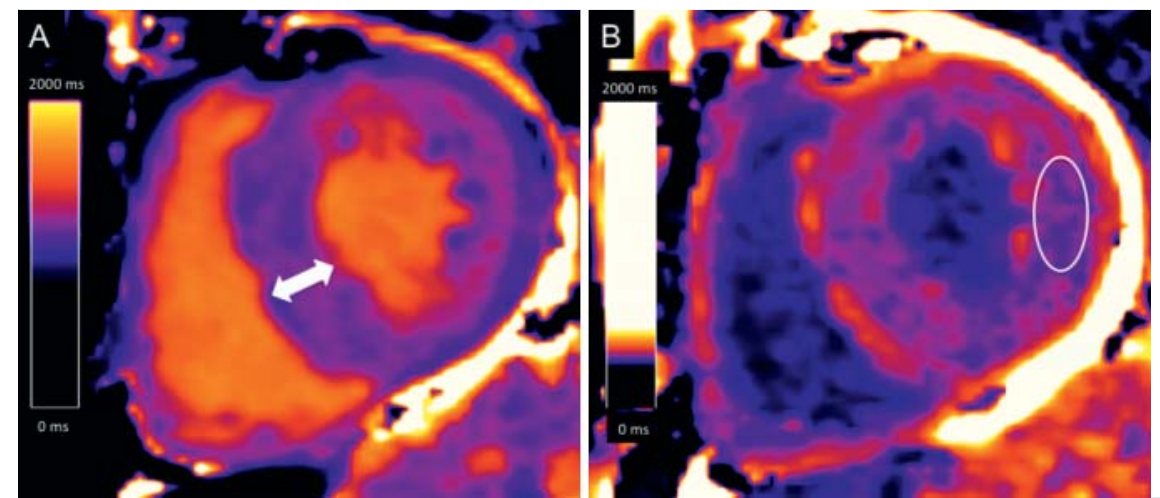

Fig. 6 Shows the pre- A and post-contrast B T1 map of a 66-year-old patient with amyloidosis at basal short axis level. Left ventricular hypertrophy with a septal diameter of $18 \mathrm{~mm}$ is present (white two-sided arrow in $\mathbf{A}$ ) and also the right ventricular myocardium is markedly thickened. Particularly the post-contrast T1 map shows a globally loosened myocardium with a variety of pixel colors, for example within the lateral wall in the white circle. The corresponding myocardial pre- and post-contrast $\mathrm{T} 1$ times are $1234 \mathrm{~ms}$ and $365 \mathrm{~ms}$, respectively, and the ECV is 0.43 . The native $\mathrm{T} 1$ and the ECV are greatly increased with respect to the current state of knowledge, compatible with amyloidosis.
Abb. 6 Zeigt eine natives T1-Mapping-Bild A sowie ein postkontrast T1Mapping-Bild $\mathbf{B}$ bei einem 66-jährigen Patienten mit Amyloidose auf basalen Kurzachsenschnitten. Es besteht eine deutliche linksventrikuläre Hypertrophie mit einem septalen Diameter von $18 \mathrm{~mm}$ (weißer Pfeil), zudem ist auch der rechte Ventrikel wandverdickt. Innerhalb des "weißen Kreises“ in der Lateralwand erscheint das Myokard deutlich aufgelockert mit unterschiedlich farbigen Pixeln. Die native T1-Zeit ist auf $1234 \mathrm{~ms}$ und das ECV ist auf 0,43 erhöht. Diese Werte bestätigen nach dem derzeitigen wissenschaftlichen Kenntnisstand eine kardiale Beteiligung im Rahmen der Amyloidose.
A recent study by Fontana et al. showed that native T1 mapping even offers potential for the differentiation of AL amyloidosis and transthyretin amyloidosis [63]. Due to the absence of edema in amyloidosis, no T2 alterations are detected. $\bullet$ Fig. 6 shows the T1 maps pre and post contrast media administration in a 66year-old female patient with amyloidosis.

\section{Anderson Fabry Disease (AFD)}

AFD is an X-linked disorder of lysosomal metabolism with an inability to catabolize glycosphingolipid (more precisely globotriaosylceramide) due to a deficiency of the enzyme alpha-galactosidase [64]. Glycosphingolipid accumulates in many organs including the skin, myocardium and kidneys. The classic form of the disease affects male homozygotes and presents in adolescence with burning extremity pain (acroparesthesia) and progressive multi-organ failure [65]. AFD can cause left ventricular hypertrophy (LVH) due to storage of glycosphingolipid in myocytes, valves and vascular endothelium [66]. The cardiac decompensation in AFD is secondary to progressive myocardial fibrosis and is usually more extensive in men than in affected women [64]. Heterozygous female carriers may therefore present with milder disease forms [67]. Like described for other cardiomyopathies, CMR is the imaging technique of choice in suspected cardiac AFD involvement. LGE within the basal infero-lateral wall without affecting the endocardium is characteristic for a cardiac manifestation in AFD [68]. In genetically confirmed AFD, Moon et al. demonstrated that LGE of the infero-lateral wall was present in $50 \%$ of the patients [68]. It also seems that the presence of LGE may have a prognostic value. Ries et al. showed that the presence of LGE in patients with AFD was associated with a lack of response to enzyme replacement therapy, which is maybe caused by irreversibly damaged myocardial tissue (scar) [69]. Otherwise enzyme replacement is a promising therapy option, which showed potential for the reduction of left ventricular hypertrophy in a recent long-term study [70].

As already mentioned, lipid in the form of glycosphingolipid is stored in myocytes, and lipid is known to shorten the magnetic resonance imaging parameter T1. In this context T1 mapping ap- pears very promising. Sado et al. showed that septal native T1 mapping values were significantly lower compared to other diseases and discriminated patients with AFD from other diseases with left ventricular hypertrophy without any overlap [7]. T1 values in patients with AFD also correlated inversely with left ventricular wall thickness, whereas T1 values of the infero-lateral wall were elevated when LGE was present [7]. Furthermore, Thompson et al. showed that reduced non-contrast myocardial T1 values are the most sensitive and specific cardiovascular MRI parameter in patients with AFD irrespective of sex and LV morphology and function [71]. ECV in AFD is normal compared to healthy volunteers whereas ECV is higher in other diseases [72]. As in amyloidosis T2 alterations are also not present. Fig. 7 shows the $\mathrm{T} 1$ maps pre and post contrast media administration and the corresponding LGE image at the basal short-axis in a 51year-old male patient with AFD.

\section{Takotsubo cardiomyopathy (TTC)}

Acute stress-related takotsubo cardiomyopathy (TTC) has recently emerged as a distinct entity and represents an important acute stress-related clinical disease. TTC mainly affects women and the spectrum of myocardial tissue injury is not well defined yet. Irreversible injury in TTC with LGE is not present [73]. TTC is characterized by its acute and sudden appearance with reduction of left ventricular myocardial function. Due to the acute character of TTC, edema was discussed as a potential tissue marker in TTC and Abdel-Aty et al. showed that edema was encountered in 7 TTC patients in the acute phase [74]. In their study edema was present in the mid-anterior and apical myocardium and also matched with the distribution of hypokinesis [74]. Accordingly the authors concluded that edema is a general feature of TTC and that edema imaging serves as an incremental tool for noninvasive characterization [74]. Also new insights into the pathophysiology of TTC might be provided. Recently on that basis, it could be demonstrated by Thavendiranathan et al. that T2 mapping reliably identified myocardial involvement in patients with TTC and myocardial inflammation [16]. Additionally, T2 mapping delineated greater extents of myocardial edema to all other per- 


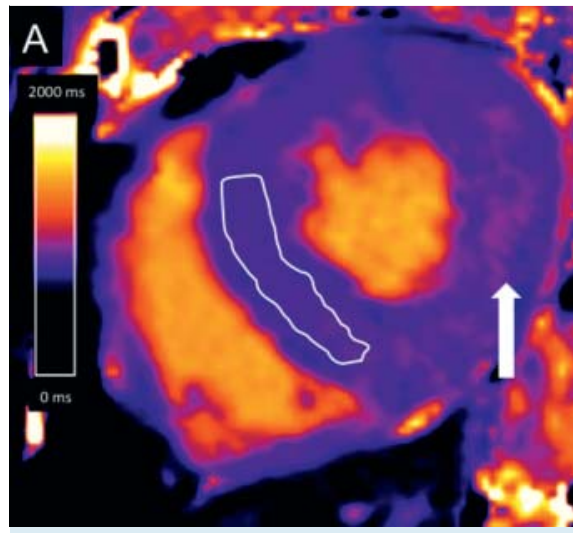

Fig. 7 Shows a native T1 map $\mathbf{A}$ and the corresponding LGE image $\mathbf{B}$ at the basal short axis in a 51-year-old male patient with Anderson Fabry disease (AFD). As a hallmark of AFD the LGE image shows an intramyocardial scar within the lateral wall, which can also be reproduced in the T1 map (white arrows). The native septal T1 time is reduced with about $860 \mathrm{~ms}$, which is compatible with cardiac involvement in AFD. Also left ventricular hypertrophy is present. The septal diameter is $21 \mathrm{~mm}$ (white two-sided arrow).

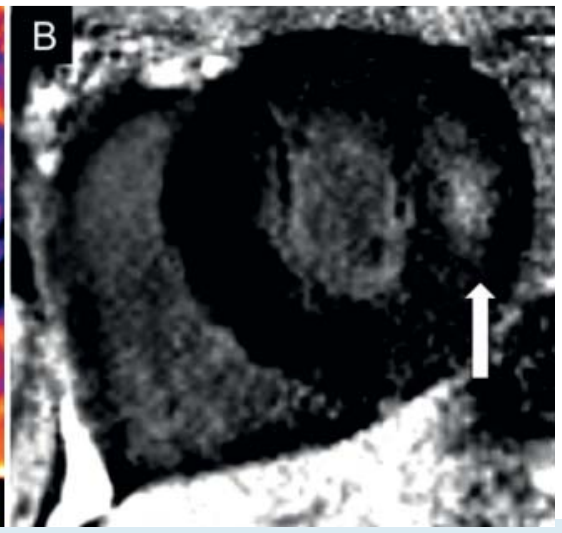

Abb.7 Zeigt ein natives T1-Mapping-Bild A sowie das korrespondierende LGE-Bild $\mathbf{B}$ bei einem 51-jährigen männlichen Patienten mit Morbus Anderson Fabry auf einem basalen Kurzachsenschnitt. Das klassische Zeichen einer myokardialen Beteiligung bei Morbus Anderson Fabry ist mit der intramyokardialen Narbe der Lateralwand gegeben, welche sich ebenfalls im T1 Mapping Bild deutlich abgrenzen lässt (weißer Pfeil). Die innerhalb des Septums gemessene native T1-Zeit beträgt $860 \mathrm{~ms}$ und ist deutlich reduziert wie für eine kardiale Beteiligung im Rahmen des Morbus Anderson Fabry gezeigt werden konnte. Der linke Ventrikel ist zudem deutlich dilatiert mit einem septal gemessenen Durchmesser von 21 mm (weißer zweiseitiger Pfeil).
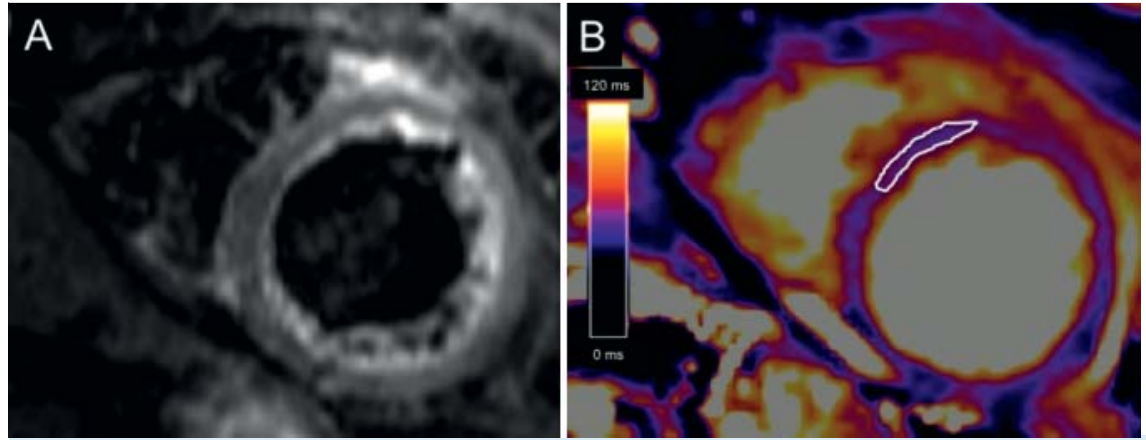

Fig. 8 Shows a "turbo inversion recovery magnitude" TIRM image $\mathbf{A}$ and a T2 map B in a 58-year-old male patient with takotsubo cardiomyopathy (TTCM) at the apical short-axis level. While edema is visually and semiquantitatively not present in the TIRM image, the measured T2 time within the ROI (white oval) in the septal myocardium is $64 \mathrm{~ms}$ and indicative for myocardial edema. Also a color difference between the septum and the lateral wall is visually present.
Abb.8 Zeigt apikale Kurzachsenschnitte aus einer „turbo inversion recovery magnitude" (TIRM) Sequenz $\mathbf{A}$ und ein T2-Mapping-Bild $\mathbf{B}$ bei einem 58jährigem Patienten mit Tako-Tsubo-Kardiomyopathie. Während sich in der TIRM-Sequenz weder visuell noch semiquantitativ ein Ödem nachweisen lässt, beträgt die im Septum gemessene T2-Zeit innerhalb der eingezeichneten ROI (weißes Oval) $64 \mathrm{~ms}$ und ist hinweisend auf das Vorliegen eines myokardialen Ödems. Auch rein visuell lässt sich im T2-Mapping-Bild eine deutliche Farbdifferenz von Septum zu Lateralwand erkennen. formed sequences [16]. $\bullet$ Fig. 8 shows a TIRM image and a T2 map at the apical short-axis level of a 58 -year-old male patient with acute onset TTC.

\section{Discussion}

Cardiac MRI is a standard diagnostic tool for a growing number of clinical issues. At present, 27 highest grade recommendations for CMR application exists in the German consensus statement [1] and a growing number can be assumed in the next couple of years. T1, T2 mapping and ECV are newer developed sequences in CMR, which are increasingly available and used in clinical routine settings. Their value in cardiac imaging is promising but challenges still remain. Mapping is a powerful tool in the identification and quantification of global or diffuse myocardial processes without further need for EMB like many studies in the recent literature showed. Also there are first signs suggesting that these new techniques detect early stages of different diseases, which were missed by other performed imaging methods or traditionally performed sequences. Mapping and ECV might also have great potential for determining the prognosis of several diseases or their values might even be used for creating endpoints in clinical trials or for therapy monitoring in the future. Due to the rapid progress and technical development with several different sequences up to now, delivery across sites and standardization are desirable objectives in the near future in order to achieve comparability between clinical excellence centers, study groups, and published values. 


\begin{tabular}{|c|c|c|c|c|}
\hline & field strength & T1 native & $\mathrm{T} 2$ & ECV \\
\hline \multirow[t]{4}{*}{ healthy subjects } & 1.5 Tesla & 968 +/- 32 ms [7] & $52.2+/-3.4 \mathrm{~ms}[30]$ & $0.25[54]$ \\
\hline & & $958+/-20 \mathrm{~ms}[6]$ & & \\
\hline & & $964+/-35 \mathrm{~ms}[54]$ & & \\
\hline & 3.0 Tesla & $1178+/-13 \mathrm{~ms}[4]$ & & \\
\hline \multicolumn{5}{|l|}{ Inflammation: } \\
\hline \multirow[t]{2}{*}{ Myocarditis } & 1.5 Tesla & $990 \mathrm{~ms}[28]^{*}$ & $59 \mathrm{~ms}[12]^{*}$ & $0.29[31]^{*}$ \\
\hline & & & $65.2+/-3.2 \mathrm{~ms}[16]$ & $>0.30[54]$ \\
\hline TTC & 1.5 Tesla & & $65.6+/-4.0 \mathrm{~ms}[16]$ & \\
\hline \multicolumn{5}{|l|}{ Cardiomyopathies: } \\
\hline \multirow[t]{2}{*}{ DCM } & 1.5 Tesla & $1056+/-62 \mathrm{~ms}$ [75] & & $0.38[54]$ \\
\hline & 3.0 Tesla & 1225 +/- $42 \mathrm{~ms}[4]$ & & \\
\hline \multirow[t]{2}{*}{$\mathrm{HCM}$} & 1.5 Tesla & & & $0.36[54]$ \\
\hline & 3.0 Tesla & $1209+/-28 \mathrm{~ms}[4]$ & & \\
\hline Amyloidosis & 1.5 Tesla & $1140+/-61 \mathrm{~ms}[6]$ & & $0.46[54]$ \\
\hline AFD & 1.5 Tesla & $882+/-47 \mathrm{~ms}[7]$ & & \\
\hline
\end{tabular}

Table 1 Reference values for $\mathrm{T} 1$, $\mathrm{T} 2$ and ECV.

Tab. 1 Referenzwerte für $\mathrm{T} 1, \mathrm{~T} 2$ und ECV.
As the case studies in this review article show, mapping is a robust technique with great potential in the imaging of different diseases. In myocardial inflammation T1, T2 mapping and ECV showed advantages compared to other imaging methods and sequences in the visualization of focal or global myocardial processes due to the quantification of T1 and T2 on a voxel-wise basis. In this context first cut-off values for T1 and T2 were published and led to improved detection of myocardial inflammation in smaller studies. The influence of mapping compared to the Lake Louise criteria in the diagnostic performance of CMR in myocardial inflammation was highly anticipated. In this context especially native T1 and ECV were detected as further improvements, as presented by Ferreira et al. and Radunski et al. [28, 31]. However, in our opinion it still remains to be seen, whether mapping will assume a decisive role in the diagnosis of myocardial inflammation with improved diagnostic accuracy and might not serve as only an increment in CMR settings. Mapping might also replace previous sequences due to radical improvement in reliability.

In different cardiomyopathies mapping also showed great potential for the detection of early disease stages even without contrast agent administration (native T1 mapping). Also degrees of fibrotic involvement are assessable without EMB. Based on these results, therapy monitoring of cardiomyopathies via follow-up examinations might be possible and clinical trial endpoints might also be reviewable. Additionally T1 mapping might be used as a prognosticator or may offer additional diagnostic benefits, and also a better understanding of the pathophysiology might be provided.

Currently mapping is not only implemented in frequently occurring diseases in CMR. Mapping also showed potential in less frequently occurring cardiac diseases in smaller studies, for example, in sarcoidosis, muscular dystrophy or chemotherapy-induced myocardial changes. The method is becoming increasingly popular and the growing number of publications dealing with cardiac mapping also supports this. Mapping has the potential to increase our understanding of pathophysiology, if interpretation is performed in context with the underlying mechanisms. - Table 1 presents published reference values for T1, T2 and $\mathrm{ECV}$ in health and disease at different field strengths.

\section{Conclusion \\ $\nabla$}

Mapping sequences are robust and increasingly available techniques, which are progressively integrated in CMR routine settings. Mapping showed promising results in many cardiac diseases and also might have the potential to change and to sustainably improve CMR diagnosis. In this context, especially clinical endpoints, prognosis, follow-up and therapy monitoring might be influenced.

\section{References}

1 Achenbach S, Barkhausen J, Beer $M$ et al. Consensus recommendations of the German Radiology Society (DRG), the German Cardiac Society (DGK) and the German Society for Pediatric Cardiology (DGPK) on the use of cardiac imaging with computed tomography and magnetic resonance imaging. Fortschr Röntgenstr 2012; 184: 345-368

2 Kellman P, Arai AE, Xue H. T1 and extracellular volume mapping in the heart: estimation of error maps and the influence of noise on precision. J Cardiovasc Magn Reson 2013; 15: 56

3 Kellman P, Hansen MS. T1-mapping in the heart: accuracy and precision. J Cardiovasc Magn Reson 2014; 16: 2

4 Dass S, Suttie JJ, Piechnik SK et al. Myocardial tissue characterization using magnetic resonance non contrast T1 mapping in hypertrophic and dilated cardiomyopathy. Circ Cardiovasc Imaging 2012; 6: 726 733

5 Ferreira VM, Piechnik SK, Dall'Armellina E et al. Non contrast T1 mapping detects acute myocardial edema with high diagnostic accuracy: a comparison to T2-weighted cardiovascular magnetic resonance. J Cardiovasc Magn Reson 2012; 14: 42

6 Karamitsos TD, Piechnik SK, Banypersad SM et al. Non-contrast T1 Mapping for the Diagnosis of Cardiac Amyloidosis. J Am Coll Cardiol Img 2013; 6: $488-497$

7 Sado DM, White SK, Piechnik SK et al. Identification and assessment of Anderson-Fabry Disease by Cardiovascular Magnetic Resonance Noncontrast myocardial T1 mapping clinical perspective. Circ Cardiovasc Imaging 2013; 6: $392-398$

8 Pedersen SF, Thrys SA, Robich MP et al. Assessment of intramyocardial hemorrhage by T1-weighted cardiovascular magnetic resonance in reperfused myocardial infarction. J Cardiovasc Magn Reson 2012; 14: 59

9 Iles L, Pfluger H, Phrommintikul A et al. Evaluation of diffuse myocardial fibrosis in heart failure with cardiac magnetic resonance contrast-enhanced T1 mapping. J Am Coll Cardiol 2008; 52: 1574-1580

10 Chan W, Duffy SJ, White DA et al. Acute left ventricular remodeling following myocardial infarction: coupling of regional healing with remote extracellular matrix expansion. J Am Coll Cardiol Img 2012; 5: $884-893$

$11 \mathrm{NgAC}$, Auger D, Delgado Vet al. Association between diffuse myocardial fibrosis by cardiac magnetic resonance contrast-enhanced T mapping 
and subclinical myocardial dysfunction in diabetic patients: a pilot study. Circ Cardiovasc Imaging 2012; 5: 51 - 59

12 Kellman $P$, Wilson JR, Xue $\mathrm{H}$ et al. Extracellular volume fraction mapping in the myocardium, part 1: evaluation of an automated method. J Cardiovasc Magn Reson 2012; 14: 63

13 White SK, Sado DM, Fontana M et al. T1 Mapping for Myocardial Extracellular Volume measurement by CMR: Bolus Only Versus Primed Infusion Technique. J Am Coll Cardiol Img 2013; 6: 955-962

14 Schelbert EB, Testa SM, Meier CG et al. Myocardial extravascular extracellular volume fraction measurement by gadolinium cardiovascular magnetic resonance in humans: slow infusion versus bolus. J Cardiovasc Magn Reson 2011; 4: 13-16

15 Wong TC, Piehler K, Meier CG et al. Association between extracellular matrix expansion quantified by cardiovascular magnetic resonance and short-term mortality. Circulation 2012; 126: 1206-1216

16 Thavendiranathan $P$, Walls $M$, Giri S et al. Improved detection of myocardial involvement in acute inflammatory cardiomyopathies using T2 Mapping. Circ Cardiovasc Imaging 2012; 5: $102-110$

17 Usman AA, Taimen K, Wasielewski M. Resonance T2 Mapping in the monitoring and follow-up of acute cardiac transplant rejection: A Pilot Study. Circ Cardiovasc Imaging 2012; 6: 782 - 790

18 Messroghli DR, Greiser A, Frohlich $M$ et al. Optimization and validation of a fully-integrated pulse sequence for modified look-locker inversion-recovery (MOLLI) T1 mapping of the heart. J Magn Reson Imaging 2007; 26: 1081 - 1086

19 Doolan A, Langlois N, Semsarian C. Causes of sudden cardiac death in young Australians. Med J Aust 2004; 180: 110-112

20 Felker GM, Thompson RE, Hare JM et al. Underlying causes and longterm survival in patients with initially unexplained cardiomyopathy. N Engl J Med 2000; 342: 1077-1084

21 Lauer B, Niederau C, Kuhl U et al. Cardiac troponin T in patients with clinically suspected myocarditis. J Am Coll Cardiol 1997; 30: 1354 1359

22 Friedrich MG, Strohm O, SchulzMenger J et al. Contrast media-enhanced magnetic resonance imaging visualizes myocardial changes in the course of viral myocarditis. Circulation 1998; 97: 1802 -1809

23 Mahrholdt H, Goedecke C, Wagner A et al. Cardiovascular magnetic resonance assessment of human myocarditis: a comparison to histology and molecular pathology. Circulation 2004; 109: 1250-1258

24 Abdel-Aty H, Boye P, Zagrosek A et al. Diagnostic performance of cardiovascular magnetic resonance in patients with suspected acute myocarditis: comparison of different approaches. J Am Coll Cardiol 2005; 45: $1815-1822$

25 Cooper LT, Baughman KL, Feldman AM et al. The role of endomyocardial biopsy in the management of cardiovascular disease: a scientific statement from the American Heart Association, the American College of Cardiology, and the European Society of Cardiology. Endorsed by the Heart Failure Society of America and the Heart Failure Association of the European Society of Cardiology. J Am Coll Cardiol 2007; 50: $1914-1931$

26 Friedrich SG, Sechtem U, Schulz-Menger J et al. Cardiovascular magnetic resonance in myocarditis: A JACC White Paper. J Am Coll Cardiol 2009; 53 (17): $1475-1487$

27 Luetkens JA, Doerner J, Thomas DK et al. Acute myocarditis: multiparametric cardiac MR imaging. Radiology 2014; 273: 383-392

28 Ferreira VM, Piechnik SK, Dall'Aremellina D et al. T1 Mapping for the Diagnosis of Acute Myocarditis Using CMR: Comparison to T2-Weighted and Late Gadolinium Enhanced Imaging. J Am Coll Cardiol Img 2013; 6: $1048-1058$

29 Hinojar R, Foote L, Arroyo Ucar E et al. Native T1 in discrimination of acute and convalescent stages in patients with clinical diagnosis of myocarditis: a proposed diagnostic algorithm using CMR. J Am Coll Cardiol Img 2015; 8: 37-46

30 Giri S, Chung YC, Merchant A et al. T2 quantification for improved detection of myocardial edema. J Cardiovasc Magn Reson 2009; 11: 56

31 Radunski UK, Lund GK, Stehning $C$ et al. CMR in patients with severe myocarditis: diagnostic value of quantitative tissue markers including extracellular volume imaging. J Am Coll Cardiol Img 2014; 7: 667-675

32 Bos JM, Towbin JA, Ackermann MJ. Diagnostic, prognostic, and therapeutic implications of genetic testing for hypertrophic cardiomyopathy. J Am Coll Cardiol 2009; 54: 201 - 211

33 Seidman JG, Seidman C. The genetic basis for cardiomyopathy: from mutation identification to mechanistic paradigms. Cell 2001; 104 : $557-567$
34 Maron BJ, Gardin JM, Fleck JM et al. Prevalence of hypertrophic cardiomyopathy in general population of young adults. Echocardiographic analysis of 4111 subjects in the cardia study. Coronary artery risk development in (young) adults. Circulation 1995; 92: 785-789

35 Decker JA, Rosano JW, Smith EO et al. Risk factors and mode of death in isolated hypertrophic cardiomyopathy in children. J Am Coll Cardiol 2009; 54: 250-254

36 Lu M, Zhao S, Yin G et al. T1 mapping for detection of left ventricular myocardial fibrosis in hypertrophic cardiomyopathy: A preliminary study. Eur J Radiol 2013; 82: 225-231

37 Kwon DH, Smedira NG, Rodriguez ER et al. Cardiac magnetic resonance detection of myocardial scarring in hypertrophic cardiomyopathy: correlation with histopathology and prevalence of ventricular tachycardia. J Am Coll Cardiol 2009; 54: 242-249

38 Prinz C, van Buuren F, Faber L et al. Myocardial fibrosis is associated with biventricular dysfunction in patients with hypertrophic cardiomyopathy. Echocardiography 2012; 29: 438 - 444

39 Bongioanni S, Spirito P, Masi AS et al. Extensive myocardial fibrosis in a patient with hypertrophic cardiomyopathy and ventricular tachycardia without traditional high-risk features. Circ Cardiovasc Imaging 2009; $2: 349-350$

40 O'Hanlon R, Grasso A, Roughton M et al. Prognostic significance of myocardial fibrosis in hypertrophic cardiomyopathy. J Am Coll Cardiol 2010; 56: 867-874

41 Hoy CJLB, Coehlo-Filho H, Lakdawala NK et al. Myocardial fibrosis as an early manifestation of hypertrophic cardiomyopathy. N Engl J Med 2010; 363: $552-563$

42 Bruder O, Wagner A, Jensen CJ et al. Myocardial scar visualized by cardiovascular magnetic resonance imaging predicts major adverse events in patients with hypertrophic cardiomyopathy. J Am Coll Cardiol 2010; 56: $875-887$

43 Kim RJ, Judd RM. Gadolinium-enhanced magnetic resonance imaging in hypertrophic cardiomyopathy: in vivo imaging of the pathologic substrate for premature cardiac death? J Am Coll Cardiol 2003; 41 : $1568-1572$

44 Varnava AM, Elliott PM, Sharma S et al. Hypertrophic cardiomyopathy: the interrelation of disarray, fibrosis, and small vessel disease. Heart 2000; 84: 476-482

45 Iles L, Pfluger H, Phrommintikul A et al. Evaluation of diffuse myocardial fibrosis in heart failure with cardiac magnetic resonance contrast-enhanced T1 mapping. J Am Coll Cardiol 2008; 52: 1574-1580

46 Sibley CT, Noureldin RA, Gai N et al. T1 Mapping in Cardiomyopathy at Cardiac MR: Comparison with Endomyocardial Biopsy. Radiology 2012; 265: 724-732

$47 \mathrm{Lu} \mathrm{M}$, Zhao S, Yin G et al. T1 mapping for detection of left ventricular myocardial fibrosis in hypertrophic cardiomyopathy: A preliminary study. Eur J Radiol 2013; 82: 225-231

48 Fang $L$, Beale A, Ellims AH et al. Associations Between Fibrocytes and Postcontrast Myocardial T1 Times in Hypertrophic Cardiomyopathy. J Am Heart Assoc 2013; 2: e000270

49 Watkins H, Ashrafian H, Redwood C. Inherited Cardiomyopathies. N Engl J Med 2011; 364: 1643 - 1656

50 Towbin JA, Bowles NE. The failing heart. Nature 2002; 415: 227-233

51 Hoe CJ, Seidman CE. A contemporary approach to hypertrophic cardiomyopathy. Circulation 2006; 113: e858-e862

52 Assomull RG, Prasad SK, Lyne J et al. Cardiovascular magnetic resonance, fibrosis, and prognosis in dilated cardiomyopathy. J Am Coll Cardiol 2006; 48: 1977-1985

53 Puntmann VO, Voigt T, Chen $Z$ et al. Native T1 mapping in differentiation of normal myocardium from diffuse disease in hypertrophic and dilated cardiomyopathy. J Am Coll Cardiol Img 2013; 6: 475-484

54 Kellman $P$, Wilson JR, Xue $H$ et al. Extracellular volume fraction mapping in the myocardium, part 2: initial clinical experience. J Cardiovasc Magn Reson 2012; 14: 64

55 Nishii T, Kono AK, Shigeru M et al. Cardiovascular magnetic resonance T2 mapping can detect myocardial edema in idiopathic dilated cardiomyopathy. Int J Cardiovasc Imaging 2014; 30 (Suppl 1): 65 - 72

56 Banypersad SM, Moon JC, Whelan C et al. Updates in cardiac amyloidosis: a review. J Am Heart Assoc 2012; 1: e000364

57 Selvanayagam JB, Hawkins PN, Paul B et al. Evaluation and management of the cardiac amyloidosis. J Am Coll Cardiol 2007; 50: 2101 2110

58 Falk RH. Cardiac amyloidosis: a treatable disease, often overlooked. Circulation 2011; 124: 1079-1085 
59 Austin BA, Tang WH, Rodriguez ER et al. Delayed hyper-enhancementmagnetic resonance imaging provides incremental diagnostic and prognostic utility in suspected cardiac amyloidosis. J Am Coll Cardiol Img 2009; 2: 1369-1377

60 Maceira AM, Joshi J, Prasad SK et al. Cardiovascular magnetic resonance in cardiac amyloidosis. Circulation 2005; 111: 186-193

61 Maceira AM, Prasad SK, Hawkins PN et al. Cardiovascular magnetic resonance and prognosis in cardiac amyloidosis. J Cardiovasc Magn Reson 2008; 10: 54

62 Syed IS, Glockner JF, Feng $D$ et al. Role of cardiac magnetic resonance imaging in the detection of cardiac amyloidosis. J Am Coll Cardiol Img 2010; 3: $155-164$

63 Fontana M, Banypersad SM, Treibel TA et al. Native T1 Mapping in Transthyretin Amyloidosis. J Am Coll Cardiol Img 2014; 7: 157-165

64 MacDermot KD, Holmes A, Miners AH. Anderson-Fabry disease: clinicalmanifestations and impact of disease in a cohort of 98 hemizygous males. J Med Genet 2001; 38: 750e60

65 Hoey ET, Neil-Gallagher E. Utility of gadolinium enhancedcardiovascular MRI to differentiate Fabry's disease from other causes of hypertrophic cardiomyopathy. Postgrad Med J 2012; 88 (1046): 731 - 732

66 Eng CM, Guffon N, Wilcox WR et al. Safety and efficacy of recombinant human alpha-galactosidase A-replacement therapy in Fabry's disease. N Engl J Med 2001; 345: 9-16

67 Messalli G, Imbriaco M, Avitabile G et al. Role of cardiac MRI in evaluating patients with Anderson-Fabry disease: assessing cardiac effects of long-term enzyme replacement therapy. Radiol Med 2012; 117: $19-28$
68 Moon JC, Sachdev B, Elkington AG et al. Gadolinium enhanced cardiovascularmagnetic resonance in Anderson-Fabry disease: evidence for a disease specific abnormality of the myocardial interstitium. Eur Heart J 2003; 24: 2151e5

69 Ries M, Clarke JT, Whybra C et al. Enzyme-replacement therapy with agalisade alfa in children with Fabry disease. Pediatrics 2006; 118: $924 \mathrm{e} 32$

70 Collin C, Briet M, Tran TC et al. Long-term changes in arterial structure and function and left ventricular geometry after enzyme replacement therapy in patients affected with Fabry disease. Eur J Prev Cardiol 2012; 19: 43-54

71 Thompson RB, Chow K, Khan A et al. T1 mapping with cardiovascular MRI is highly sensitive for Fabry disease independent of hypertrophy and sex. Circ Cardiovasc Imaging 2013; 6: 637-645

72 Sado DM, Flett AS, Banypersad SM et al. Cardiovascular magnetic resonance measurement of myocardial extracellular volume in health and disease. Heart 2012; 98: 1436 - 1441

73 Wittstein IS, Thiemann DR, Lima JA et al. Neurohumoral features of myocardial stunning due to sudden emotional stress. N Engl J Med 2005; 352: 539-548

74 Abdel-Aty H, Cocker M, Friedrich MG. Myocardial edema is a feature of Tako-Tsubo cardiomyopathy and is related to the severity of systolic dysfunction: insights from T2-weighted cardiovascular magnetic resonance. Int J Cardiol 2009; 132: 291 - 293

75 Aus dem Siepen F, Buss SJ, Messroghli D et al. T1 mapping in dilated cardiomyopathy with cardiac magnetic resonance: quantification of diffuse myocardial fibrosis and comparison with endomyocardial biopsy. Eur Heart J Cardiovasc Imaging 2015; 16: 210-216 